ticas para dar nuevos pasos en la vía de un desarrollo humano para todos los pueblos de la tierra!

Ildefonso Camacho Laraña S. J .

\section{DERECHO MERCANTIL}

Sánchez Calero, F. (2001), La sociedad cotizada en Bolsa en la evolución del derecho de Sociedades, discurso leído el día 26 de marzo de 2001 en el acto de recepción como académico de número y contestación del Excmo. Sr. D. Aurelio Menéndez Menéndez, Real Academia de Jurisprudencia y Legislación, 368 págs.

La sociedad anónima, erigida desde su creación -hace de ello más de tres siglos- como el motor del sistema capitalista, ha ido adaptándose a los influjos y exigencias que los intereses económicos dominantes de cada época imponían. Ya el maestro Garrigues advertía en 1933 cómo esta "especie de perpetuum mobile sigue viviendo y sale vigorizada de los múltiples conflictos que en su estructura cada día plantea la nueva economía". Es lo cierto, sin embargo, que tales modificaciones traen consigo una inevitable desvirtuación con respecto al régimen plasmado por el legislador, por lo que una atenta observación a esta "nueva" y "globalizada" economía pone de manifiesto la existencia de lo que se ha venido en denominar el divorcio entre la realidad vivida en las sociedades anónimas coti- zadas - "aquellas que tienen admitidas a negociación en una Bolsa española todas o parte de sus acciones", según la definición contenida en el Real Decreto de 15 de marzo de 1991- de la regulación legal existente, contenida en la LSA de 1989. En efecto, nuestra Ley, a modo de "lecho de Proscuto", resulta excesivamente amplia para la mayoría de las sociedades cerradas pero, al mismo tiempo, insuficiente y corta para las sociedades cotizadas.

Pues bien, el Excmo. Sr. D. Fernando Sánchez Calero, con ocasión del acto de su nombramiento como Académico de número en la Real Academia de Jurisprudencia y Legislación, ha elaborado un interesantísimo estudio en el que "intenta trazar (a modo de lege ferenda) las líneas generales de una eventual regulación específica de la sociedad que accede a la Bolsa para que se coticen sus acciones" (p. 25), siendo toda esta obra un alegato en favor de una reforma jurídica tan ansiada en esta materia.

La gran masa de pequeños inversores que acontecen en la gran sociedad anónima hace ya mucho tiempo que ha decidido no intervenir en la marcha de la vida de la sociedad, guardando la afectio societatis en el fondo del baúl de los recuerdos, terminando por convertirse realmente en meros inversores, más preocupados por la cotización de sus acciones en el Mercado de Valores que en una participación activa en la sociedad. Sería muy ingenuo por nuestra parte pensar que esta transformación se produce de manera aislada; por el contrario, está ligada a otros fenómenos de igual o mayor trascendencia, como son el alejamiento del ideal democrático inspirador de nuestro Código de 
Comercio y nuestras Leyes sobre sociedades anónimas, y la aparición en el seno del accionariado de un capital de control, posicionado como contra punto del llamado capital de ahorro, es decir, el formado por aquellos accionistas-inversores, lo cual supone un retroceso de la peregrinación hacia la consecución de la democracia como principio inspirador del régimen societario, volviendo a sus orígenes aristocráticos.

De ahí que, ante este divorcio, urge la necesidad de una reforma jurídica que vuelva sus ojos a la realidad. La aparición de nuevos hechos, tales como la globalización, la evolución en la negociación de los valores, la creación de mecanismos para estabilizar el control mayoritario de control, reclaman un nuevo derecho. Ahora bien, como señala el autor, esa nueva normatividad se tiene que engendrar desde el propio seno del derecho de sociedades y no por la vía del desarrollo del Derecho regulador del Mercado de Valores. En efecto, parte de nuestra doctrina mantiene que el régimen de la sociedad cotizada se resolvería plenamente con el simple hecho de insertarla en el seno del Derecho del Mercado de Valores, en el Derecho de la Bolsa. Ciertamente, la tutela que los inversores reciben por parte de dicho Derecho incide de lleno en el régimen de la Sociedad Anónima, por lo que es lícito reconocer la existencia de una estrecha interconexión entre las normas del Derecho de sociedadesy las normas reguladoras del Mercado de Valores. Sin embargo, esta vía no es suficiente para la resolución de los problemas sustantivos que acaecen en el corazón de la gran sociedad anónima y delos grupos desociedades-entre otras razones cabe argumentar la ineptitud del Derecho del Mercado de Valores a la hora de establecer la estructura de la sociedad anónima, el régimen de sus órganos y los derechos de los accionistas-. Por tanto, la problemática queplantea la sociedad cotizada debe intentar sanarse a través de reformas legislativas del Derecho de sociedades. Este es justamente el propósito del presente trabajo recensionado: el estudio y formulación del posible régimen jurídico que, a modo de lege ferenda, debería insertarse en la posible futura Ley de sociedades Anónimas que coticen en Bolsa todas o parte de sus acciones.

Del pormenorizado desarrollo realizado de todos y cada uno de los aspectos que plantearía el régimen de la sociedad anónima cotizada -adquisición de la condición de sociedad anónima cotizada, capital mínimo, número de acciones que coticen en Bolsa, cambio de régimen a sociedad cotizada, la noción de "minoría", el régimen de las acciones de la sociedad, las acciones especiales, los pactos parasociales, la organización de la sociedad y la regulación general de los grupos en el marco del Derecho de sociedades- quizás sea, como bien señala $D$. Aurelio Menéndez Menéndez en la constestación al discurso del profesor Sánchez Calero, el apartado correspondiente a la organización y administración de la sociedad cotizada el que merece prestar una mayor atención.

Es de agradecer el anhelo que el autor expresa en esta obra por recuperar en cuanto se considere posible la significación originaria y democrática de la J unta General mediante una mayor y más efectiva participación de los socios 
inversores en las reuniones. Efectivamente, aspectos como la gran masa de accionistas inversores con los que cuentan estas sociedades cotizadas y que se encuentran alejados, no sólo en el campo espiritual dela afectio societatis sino también en el mero plano físico, de la celebración de la Junta General; el dominio en dicha Junta de la mayoría de control y de los administradores nombrados por ella; el desinterés y la falta decompetencia técnica o económica de una buena parte de los que asisten a la reunión, etc... alteran sustancialmente la tradicional función normal de supervisión de la vida social, hasta tal punto queda desvirtuada que se ha convertido en un órgano dependiente del Consejo de Administración, quedando así como reliquia histórica la concepción ya romántica de la misma como órgano soberano de la sociedad. Sin embargo, como el propio Sánchez Calero reconoce, son tantas las limitaciones y dificultades que la J unta General padece que las propuestas efectuadas en esta obra para su revitalización (entre otras, promover el establecimiento del deber de la propia Junta de procurar su autorregulación mediantelaformulación y aprobación de un reglamento de funcionamiento de la misma, contenido dentro de los límites señalados por la ley y los estatutos) no pasan de tener una efectividad un tanto modesta.

El punto decisivo del libro se encuentra en el apartado dedicado al estudio de la administración de la sociedad cotizada, no obstante se trata de la cuestión de la lucha por el poder y el control de aquellas sociedades mercantiles que cuentan con un accionariad o numeroso y cambiante y que, en definitiva, consti- tuyen la riqueza de nuestro país. En este orden de cosas, la irrupción en España del movimiento reformador del llamado "Gobierno corporativo" (Corporate Governance) a través del "Código de Buen Gobierno", también conocido por referencia al Presidentequelo elaboró como "Código Olivencia", ha desencadenado en nuestra doctrina toda una serie de reacciones tanto a favor como en contra de sus nuevos postulados. Dicho movimiento, fiel a una ideología neoliberal y movid o bajo la visión del análisis económico del Derecho, se posiciona alejado de toda disciplina jurídica, siendo su ámbito de actuación la autonomía privada, es decir, por singular decisión del Gobierno español se ha optado por seguir un método o vía típicamente anglosajón consistente en utilizar Códigos de autorregulación o autodisciplina que, en sí, sólo contienen recomendaciones sin valor normativo pero con un alto grado de "eficacia competitiva", en el sentido de que su adhesión es susceptible deconferir un "capital reputacional" proporcionado por el mercado. Así el propio Código Olivencia afirma en la tercera de sus Condiciones generales que "no se trata de proponer normas de Derecho objetivo, sino de ofrecer a la consideración de las sociedades destinatarias un catálogo de medidas que en uso de la libre autonomía de la voluntad y de la facultad de autorregulación que nuestro ordenamiento jurídico les reconoce, podrán adoptar en sus estatutos o reglas defuncionamiento orgánico". Este nuevo método de hacer derecho y de regular el sistema de administración y control de aquellas sociedades que deseen cotizar en un Mercado de Valores (inspirado en la cultura y experiencia societaria anglosajona) presenta un di- 
fícil encuadre en nuestra cultura jurídica, amén de sus no pocas disfunciones con el Derecho positivo vigente contenido en nuestra Ley de Sociedades Anónimas. La polémica está servida: desregulación contra normatividad. Anteesta dicotomía, Sánchez Calero aboga acertadamente por la labor legislativa, más acorde con nuestra tradición jurídica, tanto española como europea-continental. Ciertamente, dicha labor legislativa "ha de estimarse necesaria a los efectos de adecuar el régimen de la sociedad anónima cotizada a las necesidades presentes sin que sean suficientes las simples normas de conducta sin la eficacia que puede dar el ordenamiento jurídico"(p.230). Ahora bien, una apuesta por una regulación normativa denuestras grandes sociedades anónimas -de las que dependen la riqueza nacionalno significa una anulación de la libertad, ni de la autonomía privada, sino que puedey debe suponer todo lo contrario, ya que hay que tener presente la necesidad, puesta de manifiesto por el movimiento del gobierno corporativo, de una mayor incorporación y mantenimiento de espacios de autonomía, es decir, la necesidad de una mayor flexibilidad.

En este orden de cosas, se agradece la advertencia que el autor realiza con respecto a la pretensión del Código de Buen Gobierno de despojar al Consejo de la función de gestión societaria que confía al "equipo de dirección", dependiente del control por parte del Consejo, pero ajeno a él. En efecto, el Código Olivencia reitera hasta la saciedad la idea detransformar al Consejo de Administración en un órgano de supervisión y control, alejado de cualquier posibilidad de gestión, puesto que "por su fun- cionamiento discontinuo, por su estructura colegiada y por su carácter deliberante, no es el órgano idóneo para llevar a cabo la administración de aquellas empresas", por lo que "el Consejo de Administración debe configurarse básicamente como instrumento de supervisión y control" (II.1.1). Frente a tal afirmación, tanto Sánchez Calero como la mayor parte de la doctrina, partiendo de que en nuestro ordenamiento jurídico rige el sistema monista, afirman que el órgano de administración asume al propio tiempo las funciones de administración y control, por lo que jurídicamente, ni siquiera por el estatuto de la delegación, el Consejo no perdería sus funciones de administrar la sociedad.

Por lo demás, la consideración que tanto para el profesor Sánchez Calero, como el profesor Menénedez Menéndez merecen el Informe redactado por la "Comisión Especial para el estudio de un Código Ético de los Consejos de Administración", así como el "Código de Buen Gobierno" no resulta sumamente negativa: constituyen "elementos altamente valiosos para una labor legislativa que haya de afrontar esta materia". De manera que, partiendo de esta afirmación, el capítulo destinado al Consejo de Administración discurre siguiendo el tenor de las recomendaciones 0 propuestas dadas por el Informe, el "Código de Buen Gobierno" y, en menor medida, el "Reglamento Tipo del Consejo de Administración ajustado al Código de Buen Gobierno", defendiéndolas en algunos casos y propugnando, otras veces, soluciones positivas distintas $y$, en su opinión, más acordes con la referida administración de las sociedades cotizadas. 
En definitiva, tenemos en nuestras manos una aportación doctrinal valiosísima para aquellos que quieran adentrarse y conocer en profundidad la configuración de la sociedad cotizada como un subtipo de la sociedad anónima, y proporciona, como bien señala Menénedez Menéndez, "un apoyo de considerable importancia a los esfuerzos que viene realizando la Sección de Derecho Mercantil de la Comisión General de Codificación en favor de la preparación, ya muy avanzada, de un Código de las sociedades mercantiles".

José Manuel Serrano Cañas 